Comparative Philosophy Volume 6, No. 1 (2015): 91-110

Open Access / ISSN 2151-6014

www.comparativephilosophy.org

\title{
HEALTH AS HUMAN NATURE AND CRITIQUE OF CULTURE IN NIETZSCHE AND ZHUANG ZI
}

\author{
DANESH SINGH
}

\begin{abstract}
Nietzsche and Zhuang Zi endorse a notion of health that relies on a theory of human nature, in the sense that health is achieved when individuals live in accordance with their nature. In order to lead healthy human lives, individuals must disabuse themselves of pernicious cultural influences. Nietzsche believes that will to power and its constituent parts, including desire and suffering, are an expression of human nature. Nietzsche opposes ascetic morality on the grounds that it requires that humans deny basic human desires and strive to eliminate human suffering. Zhuang Zi understands health as the perfection or wholeness of de, which involves the acceptance of fate, a state in which individuals are at ease with the inevitable, and lack strong evaluative attitudes and preferences and aversions, a product of culture. I will argue that Zhuangist health includes elements of physical health, such as living out one's allotted span of years and avoiding harm by being useless. Zhuang Zi's endorsement of physical health seems incompatible with the fact that his Daoist exemplars are sometimes disfigured and mutilated. While physical health is an important aspect in Zhuangist health, psychological health is sufficient, as evidenced in two stories that employ the notion of wholeness of de.
\end{abstract}

Keywords: Nietzsche; Zhuang Zi; health; human nature; culture

Nietzsche and Zhuang Zi (莊子) believe that what humans fundamentally are provides a basis for how they ought to live. The normative health of human beings, according to this view, is achieved when they live in accordance with that which they essentially are. Both Nietzsche and Zhuang Zi characterize their normative visions in terms of the category of health. Their respective notions of health are predicated on appeals to what is natural for human beings, and these appeals to nature serve as constraints for how humans ought to live. In addition, both thinkers are concerned with disabusing individuals of harmful cultural influences that serve as an obstacle to leading healthy human lives. Insofar as their respective normative visions set as their target the goal of living naturally, free of pernicious cultural influences, we can understand their respective projects as promoting a notion of normative health. In

SINGH, DANESH: Department of Philosophy, Binghamton University, USA. Email: danesh.singh@gmail.com 
this study, I hope to bring together some of the existing literature in Nietzsche studies and put it in dialogue with the philosophical literature on Zhuang $\mathrm{Zi}$, in order to show how the normative visions of both philosophers display this therapeutic quality.

Nietzsche understands will to power to be the ultimate expression of human life. Drives express will to power in the sense that they strive towards dominance over the self. Health is achieved when drives overcome resistance coming from competing drives in the fulfillment of a particular desire. Nietzsche offers a critique of ascetic morality on the grounds that it stands opposed to the structure of will to power. Will to power, as a description of human nature, manifests in healthy and unhealthy ways, in the sense that will to power can create accord or conflict in the psyche. Specifically, ascetic morality is opposed to will to power in that it denies basic human desires and strives to eliminate all human suffering, two essential components in the structure of will to power. Nietzsche wishes to replace ascetic morality with a new set of value standards that are continuous with will to power, standards that endorse self-regarding desires as well as the art of experiment.

A therapeutic reading of Nietzsche's philosophy illuminates a similar concern with normative health in the thought of Zhuang Zi. He, like Nietzsche, makes appeals to nature and the natural that are descriptive and normative in content. The full and free development or perfection of $d e$ (zhi-de 至德), also referred to as the wholeness of de (quan-de 全德), the natural ability inherent to all things in virtue of being the kinds of things that they are, is essential to the attainment of the normative Way (dao 道) and to Zhuang Zi's robust notion of normative health.

The perfection or wholeness of de describes the psychological and specifically emotional aspect of health in Zhuang Zi's thought. Following Fraser, I understand this psychological aspect to refer to the acceptance of fate (ming 命). Individuals confront situations and pressures about which they cannot do anything (bu-ke-nai-he 不可奈何); the goal is to be at ease (an 安) with the inevitable (bu-de-yi 不得已). Importantly, this psychological aspect of health places specific importance on the emotional lives of individuals. When individuals cultivate their de, intense emotions that disturb this inner calm can no longer threaten their equanimity. For Zhuang Zi, intense emotions that express joy, anger, sorrow, and delight are the result of individuals taking on the wrong cognitive and evaluative attitudes about right and wrong ( $s h i-f e i$ 是非) or the wrong preferences and aversions (hao-wu 好惡) towards things. Zhuang $\mathrm{Zi}$ thinks that these attitudes and preferences and aversions are the result of pernicious cultural influences that take individuals away from their nature.

Fraser's reading of Zhuang Zi's philosophy does not include a set of concepts that describe physical health. In this study, I explore the ways in which Zhuang Zi discusses the physical aspects of health as part of his therapeutic project. In addition to the psychological concept of perfection or wholeness of de, Zhuang $\mathrm{Zi}$ endorses elements of physical health, including living out one's allotted span of years (jin-nian 盡年, zhong-qi-tian-nian 終其天年) as well as keeping oneself physically whole and free from various harms and deprivations by being useless (wu-yong 無用, wu-suo-ke 
yong 無所可用). I will discuss Zhuang Zi's treatment of physical health in order to clarify the role of physical health in Zhuang Zi's broader notion of health.

At first blush, the notion that physical health is important to Zhuang Zi's therapeutic project seems counterintuitive, since this would commit him to the view that individuals must keep their bodies intact in order to achieve robust normative health. This view does not seem to square with the fact that many of Zhuang Zi's Daoist exemplars, such as Crippled Shu and Shu Shan No-Toes, are mutilated or disfigured. I will argue that living out one's allotted years and avoiding harm by being useless is a mark of living naturally and hence an expression of health, even as the psychological aspect of health is primary. Zhuang $\mathrm{Zi}$ explains in two stories from the fifth chapter that "wholeness of $d e$ " (quan-de), which pertains solely to psychological and emotional health, is more important than physical or bodily (xing 形) integrity. Zhuang $\mathrm{Zi}$ even suggests in these passages that wholeness of de is sufficient to normative health.

\section{HEALTH AS A THEORY OF NATURE AND CRITIQUE OF CULTURE}

The philosophical category of health that I develop in this comparative study will contend that descriptive metaphysics provides a basis for normative ethics. It is a value laden account, in the sense that descriptive features of human nature are picked out as relevant to a normative account of how human beings ought to live. Martha Nussbaum rightly understands Aristotle's ethical view in terms of the normative concept of health that is associated with much ethical theory that emerged in ancient Greek thought. For Aristotle, the full flourishing of humans' moral nature should be understood as engaging in activities that are expressive of their most essential capabilities, without the impediments that serve as obstacles to it. (Nussbaum 1994, 30-31) Like other early Ancient Greek thinkers, Aristotle employs medical analogies in order to draw out a similarity between the aim of doctors to heal diseased bodies and the aim of philosophers to heal the soul of its maladies or impediments. (Aristotle 1999, 7) Nietzsche and Zhuang Zi, like Aristotle, pose arguments that depend on a general description of nature. In the same way that Aristotle relies on explanations of what is natural to establish his normative commitments, Nietzsche and Zhuang Zi will also pick out important features of nature in order to develop their respective normative concepts of health.

Separate from her reading of Aristotle, Nussbaum highlights the ways pernicious cultural influences alienate humans from their nature. To articulate this aspect of the Greek notion of health, Nussbaum departs from Aristotle and relies instead on the Hellenistic philosophers, particularly the Stoics. (Nussbaum 1994) Nietzsche and Zhuang Zi, like the Stoics, see culture as a significant threat to the realization of their respective normative visions, and they believe, also like the Stoics, that in order to achieve a state of health, individuals must first disabuse themselves of prejudices that serve as an obstacle to normative health. ${ }^{1}$

\footnotetext{
${ }^{1}$ For a comparison of Nietzsche and Zhuang $\mathrm{Zi}$ on the theme of cultural critique, see Hall (1984).
} 


\section{NIETZSCHE AND HEALTH AS A THEORY OF NATURE}

In order to make better sense of the structure of will to power, it is important to understand it in the context of a drive theory that Nietzsche employs to describe the self. For Nietzsche, the self is composed of sub-personal elements called drives. For Nietzsche, drives are dispositions that express themselves by structuring the agent's perceptions, affects, and even reflective thought. (Katsafanas 2013) According to Nietzsche's drive theory, the self does not start out as a unified subject. ${ }^{2}$ Since there is no substratum that ties the drives together, the subject is generally composed of drives that are deeply contradictory. Accordingly, the drives are in constant competition with one another, each vying for control and dominance over the others. ${ }^{3}$ On Nietzsche's view, the self is a platform for the struggle of the drives to play out. (Leiter 2002, 103) In their desire to establish authority over the self, drives exert will to power over other drives.

In the context of will to power, Nietzsche's notion is a corrective to Schopenhauer's notion of will to life. (Nietzsche 2000a, 393, Reginster 2006, 103147) Nietzsche is no doubt at the same time indebted to Schopenhauer in his formulation of will to power, in that Schopenhauer's concept also conceives of willing as a central feature of human existence. For both Nietzsche and Schopenhauer alike, happiness is understood at least partly in terms of the satisfaction of desires (Reginster 2006, 103-147). They argue that this basic striving in all wills seeks satisfaction, and once a will can satisfy all these desires, then it can finally be happy. Both also believe that the feeling of suffering results when desires are frustrated.

But Nietzsche's account of will to power differs from Schopenhauer's notion in that for Nietzsche, power plays a salient role. Singular drives seek will to power in the sense that they strive towards overcoming resistance in order to establish authority over the self. In Beyond Good and Evil, Aphorism 259, Nietzsche explains that this overcoming of resistance involves "appropriating," "injuring," "overpowering," and "exploiting" weaker drives. (Nietzsche 2000a, 393) ${ }^{4}$ In order for drives to have their desires met, they must establish authority over the self by overpowering other drives.

Nietzsche's account of will to power describes a dynamic movement that distinguishes between the drive as it strives to overcome resistance and the drive's desire to have certain concrete aims met. When drives exert power over other drives, this exertion of power does not in itself possess any particular content; its content is determined by the desire that the drive's willing directs itself towards. For Nietzsche, to say that a drive wills to power implies that it wills something other than power itself; it is also the pursuit of goals that are not yet satisfied. (Richardson 1996, 23-24,

\footnotetext{
${ }^{2}$ See Nehamas (1985, 170-199). See also Clark and Dudrick (2012) as well as Parkes (1994).

${ }^{3}$ To offer just a few examples of Nietzsche's vivid depiction of the drives in competition with one another, see Nietzsche (1997, 64-65) and Nietzsche (1997, 74-76) as well as Nietzsche (2000a, 203204).

${ }^{4}$ See also Nietzsche $(2000 \mathrm{~b}, 514-515)$ for an account of will to power as described in terms of drives overpowering other drives.
} 
Reginster 2006, 126-127) These interconnected aspects of will to power map on to first-order and second-order desires respectively. (Reginster 2006, 132) ${ }^{5}$ Will to power is the second-order desire to overcome resistance as it pursues some concrete first-order desire, which gives will to power its content. If the will to power is not merely the second-order desire to desire, but also the first-order desire to overcome resistance as it pursues some intentional object, then will to power will not be satisfied unless three conditions are met: first, there must be some first order desire; second, there must be resistance to the achievement of this first order desire; and third, there must be success in overcoming the resistance. (Reginster 2006, 135-139) It is important to note that while Nietzsche thinks that human desire is highly plastic, by their nature, humans are disposed to pursue some first-order desires rather than others; as we will see, Nietzsche believes that humans are naturally inclined to pursue sensual and rapacious desires that are fundamentally self-regarding.

Of the scholars that have understood will to power to be a natural feature that informs an ethical project, Janaway's reading is particularly helpful for the purposes of the present study. Janaway has given a reading of Nietzsche's project that includes will to power as a feature of human nature, expressive of human biology and manifest in cultural practices. (Janaway 2007, 149) ${ }^{6}$ Will to power, on Janaway's reading, manifests in healthy and unhealthy ways, in the sense that will to power can create accord or conflict in the psyche. (Janaway 2007, 146) Janaway names the ascetic priest, a proponent of ascetic ideals, as an example of an individual whose psyche is conflicted. Nietzsche calls ascetic morality a contradiction in Sections 11 (Nietzsche 2000b, 553) and 13 of the third essay. As he explains in Section 13: "It will be immediately obvious that such a self-contradiction as the ascetic appears to represent, 'life against life,' is, physiologically considered and not merely psychologically, a simple absurdity." (Nietzsche 2000b, 556) When Nietzsche calls ascetic morality a contradiction, Janaway explains that this means that the priest "genuinely grows in power (over himself) as he dissociates from and destroys his natural strength." (Janaway 2007, 146) I argue that the denial of desire and suffering, as important components of will to power, serve as a basis for Nietzsche's critique of ascetic morality, since ascetic morality requires that humans deny their natural propensities to have basic desires and to accept suffering in the sense of confronting resistance to desires.

Ascetic morality, as a pernicious cultural development, requires the denial of basic human desires, which is a key characteristic of ascetic ideals. As Leiter has pointed out, ascetic ideals are composed of norms that place value on states of selfdenial in which individuals relinquish the satisfaction of basic human desires. These include sensual and rapacious desires of the kind that are fundamentally self-

\footnotetext{
${ }^{5}$ Reginster borrows the language of first-order and second-order desires from Clark (1990, 211), who sees will to power as just the second-order desire. I follow Reginster in understanding will to power as having a two-fold structure that contains both first-order and second-order desires. Reginster's and Clark's readings employ terminology taken from Harry Frankfurt's philosophy. See Frankfurt (1971).

${ }^{6}$ In addition to Janaway, see Richardson (1996) and Schacht (1983) for readings that understand Nietzsche's notion of will to power as informing an ethical project.
} 
regarding. (Leiter 2002, 246) Nietzsche devotes the third essay of his On the Genealogy of Morals to explaining how the ascetic lifestyle, with its emphasis on self-denial, opposes human desires. (Nietzsche 2000b, 533-599) Ascetic ideals locate ultimate value in self-denial, that is, in a source that can only be found independent of what is most natural to humans. Also in the third essay, Nietzsche writes that ascetic ideals praise poverty, chastity and humility (Nietzsche 2000b, 544) as its cardinal virtues and valorizes self-denial at the expense of the satisfaction of these basic human desires in particular. Ascetic ideals are in conflict with will to power because these ideals oppose the propensity to have desires, such as those for wealth, prestige, and sexual gratification. (Leiter 2002, 246) Nietzsche believes that the very desires that are opposed by the ascetic ideal are particularly problematic, since these are the desires that are most instinctive to humans. It is in this sense that ascetic ideals deny desire and thereby deny will to power as a fact of human nature.

In the same way that the denial of desire is detrimental to living in accordance with will to power, so too is the denial of suffering. Reginster's reading of the role of suffering in Nietzsche's thought has already shown how suffering, defined in terms of resistance, is necessary to will to power. According to Reginster, Nietzsche disagrees with Schopenhauer's view concerning the role of suffering in a happy human life. (Reginster 2006, 103-147) For Schopenhauer, what underlies all striving is a desire to desire (Reginster 2006, 122). We always desire, and this desire causes pain because it leads people to experience life as lacking in some way (Reginster 2006, 109). Unsatisfied desires are by their very nature painful and thereby cause suffering, and so if happiness is possible at all, then it must consist in a cessation of all desires. (Reginster 2006, 108) Happiness, according to Schopenhauer, must be some final satisfaction of the will, in which no new desires and wants are generated. Schopenhauer would agree with the ascetic priest that the ultimate goal is to eliminate desires.

In the third essay of his Genealogy, Nietzsche attacks Schopenhauer's ascetic view that the goal of life is to extinguish all willing, in order to achieve a state of happiness in which nothing is wanting. Here, Nietzsche responds to Schopenhauer's aesthetic theory more specifically, a theory that appropriates Kant's well-known definition of the beautiful: "That is beautiful...which gives us pleasure without interest." (Nietzsche 2000b, 540) According to Nietzsche, Schopenhauer's insistence that the best kind of aesthetic appreciation is constituted by disinterested contemplation is in fact disingenuous. Nietzsche cites Schopenhauer's remark that aesthetic contemplation "counteracts sexual "interestedness" (Nietzsche 2000b, 540) as evidence that Schopenhauer's theory conceals his personal desire to extinguish the painful sexual desires that constantly tormented him. Nietzsche sees in Schopenhauer the man, and in his thought, a longing to escape the suffering that accompanies these desires. Nietzsche understands Schopenhauer's attempt to extinguish all willing through a state of disinterested contemplation as an attempt to escape all suffering. (Nietzsche 2000b, 541-542) For Nietzsche, this is problematic, since suffering is an important component of will to power. In order to eventually overcome resistance from other drives that compose the self, a given drive must first confront resistance, 
that is, confront suffering itself. As Reginster puts the point: "The will to power, insofar as it is a will to the overcoming of resistance, must necessarily also will the resistance to be overcome." (Reginster 2006, 133) For Nietzsche, without suffering, drives cannot establish authority over the self, a prerequisite to human health.

If the reading of Nietzsche given in the present study is correct, then Nietzsche's notion of will to power leads to a puzzle. The satisfaction of desires ultimately leads to its own dissatisfaction, since the achievement of the end means an end to the activity as well. Once individuals have achieved their desires, they will be frustrated, for they are deprived of the pursuit that gave will to power a goal. The puzzle is resolved in light of the fact that, for Nietzsche, built into the structure of will to power is a desire for new desires to be generated and for new resistances to be overcome.

Nietzsche's discussion of human health and sickness parallels his treatment of will to power and the puzzle that accompanies it. Nietzsche associates health with the successful overcoming of resistance and fulfillment of a given desire, and sickness with the suffering or resistance itself. Just as the drives that exert will to power require suffering, human health requires sickness. ${ }^{7}$ If health is constituted by an overcoming of resistance, then what is first required is a state of deficiency that makes possible resistance and an eventual overcoming. This is why Nietzsche doubts that we can completely do away with sickness in his notion of health. As he explains in an aphorism from The Gay Science,

Finally, the great question would still remain whether we can really dispense with illness - even for the sake of our virtue - and whether our thirst for knowledge and selfknowledge in particular does not require the sick soul as much as the healthy, and whether, in brief, the will to health alone, is not a prejudice, cowardice, and perhaps a bit of very subtle barbarism and backwardness. (Nietzsche 1974, 177). ${ }^{8}$

For Nietzsche, health should be understood as a state continually renewed as individuals pursue greater stages of health. Without sickness, there is no resistance to be overcome. If health welcomes resistance in the pursuit of increased capabilities and self-enhancement, then it must also affirm the suffering that accompanies it, since without suffering, individuals cannot face new challenges in order to reach greater states of health.

While Nietzsche allows for myriad possibilities ${ }^{9}$ concerning which set of values facilitate a state of health, what they all have in common is that they require individuals to posit values continuous with the structure of will to power. Will to power, as a fact of human nature, serves as a constraint to defining how humans ought to live. In Aphorism 44 of Beyond Good and Evil, Nietzsche likens human beings to plants in order to explain what basic values are necessary in order to lead

\footnotetext{
${ }^{7}$ For a discussion of will to power and Nietzschean health, see Letteri (1990), Long (1990), and Lawton (1987/1988).

${ }^{8}$ See also Nietzsche $(1974,37)$, where Nietzsche discusses his movement from physical and psychological sickness to a restored health.

${ }^{9}$ See Nietzsche's position that there are "innumerable healths." Nietzsche $(1974,177)$.
} 
healthy lives. People, like plants, must be properly cultivated in order to grow and flourish. While some value orientations stunt the growth of humans, others promote their growth, ${ }^{10}$ and what makes his healthy individuals different from those compelled by existing morality is that "[w]e opposite men, having opened our eyes and conscience to the question where and how the plant 'man' has so far grown most vigorously to a height — we think this has happened every time under the opposite conditions..." (Nietzsche 2000a, 244)

Nietzsche goes on in Aphorism 44 to say that modern people have generally failed to see the ways in which an individual's "power of invention and simulation (his 'spirit') had to develop under prolonged pressure and constraint into refinement and audacity," and about how "his life-will had to be enhanced into an unconditional power-will." He elaborates:

We think that hardness, forcefulness, slavery, danger in the alley and the heart, life in hiding, stoicism, the art of experiment, and devilry of every kind, that everything evil, terrible, tyrannical in man, everything in him that is kin to beasts of prey and serpents, serves the enhancement of the species "man" as much as its opposite does. ${ }^{11}$ (Nietzsche 2000a, 244-245)

Given the account of desire and suffering and their role in the structure of will to power discussed above, it is unsurprising that Nietzsche believes that a social world which develops "everything in [man] that is kin to beasts of prey and serpents" will promote human health. Modern people find these aspects of humanity awful, since for one they are based on our basic self-regarding desires, such as desires for wealth, prestige, and sexual gratification. But according to Nietzsche, these values are compelling precisely for the reason that they reflect a natural part of humanity.

It is also unsurprising that Nietzsche believes that we should promote values that facilitate "hardness," "danger," and "the art of experiment" - in direct contrast to the existing values of security, lack of danger, and comfort. ${ }^{12}$ The art of experiment refers not just to conducting experiments in order to discover new values to replace ascetic morality; it also refers to a constant and continual desire to overcome obstacles and challenges in order to achieve higher states of human health. According to Nietzsche's notion of health, there is no end-state of individual perfection (Swanton 2006, Reginster 2006, 235-242). This means that individuals must constantly oppose their most cherished values. Nietzsche discusses the necessity of opposing those values and ways of life that individuals have once embraced and come to love. He writes,

Whoever has a soul that craves to have experienced the whole range of values and

\footnotetext{
${ }^{10}$ See Geuss $(1997,9)$, where he discusses Nietzsche's plant analogy in connection to a theory of human development.

${ }^{11}$ See also Nietzsche (2000a, 323) and Nietzsche's call to "live dangerously": Nietzsche (1974, 228229).

${ }^{12}$ For an account of the character traits that Nietzsche believes best promote health, see Welshon, (2006).
} 
desiderata to date, and to have sailed around all the coasts of this ideal "mediterranean"; whoever wants to know from the adventures of his own most authentic experience how a discoverer and conqueror of the ideal feels, and also an artist, a saint, a legislator, a sage, a scholar, a pious man, a soothsayer, and one who stands divinely apart in the old styleneeds one thing above everything else: the great health - that one does not merely have but also acquires continually, and must acquire because one gives it up again and again, and must give it up. (Nietzsche 1974, 346) ${ }^{13}$

Nietzsche's notion of health, with its emphasis on constant and continual growth, implies the necessity of cultivating brief, as opposed to enduring, habits. Indeed, Nietzsche says that only brief habits can bring enduring satisfaction. (Nietzsche 1974, 236-237) While the good habit in question nourishes individuals for a time, one day it will no longer serve them, and they must part ways with it. And although Nietzsche recognizes a propensity in humans to naïvely insist that their current habits will endure permanently, in truth, for Nietzsche's healthy individuals, another habit will come along and replace it (Nietzsche 1974, 237). In light of this concept of health in which those who engage in the art of experiment apply their knowledge and have brief, as opposed to enduring, habits, individuals should be willing to abandon once deep-rooted values, in favor of others that facilitate greater stages of health of the human being.

It should not surprise us that Nietzsche endorses a notion of health that resembles Aristotle's ethics and Greek thought more generally, given Nietzsche's debt to Greek philosophy. I will argue that putting Nietzsche's therapeutic vision in dialogue with Zhuang Zi's thought can help us to see how his Daoist vision also concerns itself with the health of humans. Specifically, Zhuang Zi's vision requires that individuals follow the full and free development, or the perfection (zhi) or wholeness (quan), of their natural abilities (de), so that they may carry out healthy psychological lives. Zhuang $\mathrm{Zi}$, then, is also concerned with the full functioning of human beings, free of any unnatural influences, and his normative project can also be understood as endorsing a notion of health in a similar way to that of Nietzsche.

\section{ZHUANG ZI AND HEALTH AS A THEORY OF NATURE}

Unlike in Nietzsche's corpus, the words "health" and "therapy" do not appear in the Zhuang-Zi. There is no one term in the original that by itself conveys the notion of health that I am ultimately attributing to Zhuang Zi. As we will see below, a variety of concepts in the Zhuan-Zi pertain to nature and the natural. Through the use of different, but overlapping, concepts, Zhuang $\mathrm{Zi}$ articulates a notion of normative health in which a description of nature informs a normative project. Ivanhoe has already noted that in Daoist thought generally, one finds a bundle of concepts relating to health and well-being, such as "living out one's allotted span of years, keeping oneself physically whole and free from a variety of harms and deprivations, and enjoying psychological ease, comfort, and contentment." (Ivanhoe 2002, XXII)

${ }^{13}$ See also Nietzsche $(1968,227)$. 
Zhuang Zi's thought conforms to this general Daoist worldview. He endorses a way of life in which individuals live out their years (jin-nian, zhong-qi-tian-nian), avoid harm by being useless (wu-yong, wu-suo-ke-yong), and experience psychological and specifically emotional well-being by accepting fate (ming) and appropriately negotiating the inevitable (bu-ke-nai-he, bu-de-yi).

Zhuang Zi reserves his notion of de to refer specifically to psychological health. Feng You Lan rightly understands de to play an integral role in Zhuang Zi's view of how nature and normativity relate. Following Feng, I define de in terms of a natural ability inherent to all things in virtue of being the kinds of things that they are. As Feng explains,

...[O]ur $[d e]$ is what makes us what we are. We are happy when this $[d e]$ or natural ability of ours is fully and freely exercised, that is, when our nature is fully and freely developed. (Fung 1976, 105)

In a famous passage from the second chapter, Zhuang $\mathrm{Zi}$ points out that different species possess a different set of preferences based on the kinds of things they are. (Watson 1968, 45-46, Zhuangzi 2/64-73) Given the makeup of humans, it is impossible for them to rest while they are submerged in water, but for the loach, a kind of fish, it is absolutely necessary. Similarly, while monkeys live in trees, humans simply cannot. Living things, like deer, loaches, and trees, are different in their respective natures, and consequently, their respective abilities, or de, are also different. What all organisms share, however, is that they are all equally happy when they fully and freely exercise their $d e$.

The cultivation of de entails that sages avoid the kind of inner harm that disrupts the psychological, and especially the emotional, well-being that accompanies harmony with the normative Way (dao). Feng relates his brief discussion of $d e$ in the Zhuang-Zi to a distinction between what is of heaven (tian) ${ }^{14}$ and what is of man (ren 人). In order to explain what it means to cultivate de, Ruo of the North Sea distinguishes between what is heavenly or natural and what is human, by characterizing heaven as what is on the inside, and the human as what is on the outside (tian-zai-nei, ren-zai-wai 天在內, 人在外). (Watson 1968, 183, Zhuangzi 17/50) Ruo discusses what is human in terms of artifice: "Putting a halter on the horse's head, piercing the ox's nose - this is what I mean by the human (ren)." (Watson 1968, 183, Zhuangzi 17/52) Human artifice has managed to do harm to nature. When the artificial overcomes what is natural, it is impossible for nature to take its course and for things to harmonize with the normative Way (dao).

Fraser's reading of Zhuang $\mathrm{Zi}$ offers an excellent analysis of the role of the perfection of de (zhi-de) in Zhuang Zi's therapeutic project. (Fraser 2011, 98-100) Specifically, he believes that for Zhuang $\mathrm{Zi}$, the perfection of de is a psychological

\footnotetext{
${ }^{14}$ For examples of the use of tian in the Zhuang-Zi, see Watson (1968, 56), Zhuangzi 4/18; Watson (1968, 75), Zhuangzi 5/53-55; Watson (1968, 87), Zhuangzi 6/74; Watson (1968, 78), Zhuangzi 6/7; Watson (1968, 40), Zhuangzi 2/29; Watson (1968, 41), Zhuangzi 2/39-40.
} 
concept that describes an acceptance of fate (ming) in which individuals are at ease (an) with the inevitable (bu-ke-nai-he, bu-de-yi). As part of his reading of Zhuang Zi's view of psychological health, Fraser pays special attention to the role of the emotions. The acceptance of fate and the inevitable should facilitate a state of affective equanimity, in which intense emotions are ruled out. (Fraser 2011)

Fraser cites several examples of Daoist exemplars who embody perfection of $d e$. Among these examples is Wang Tai, an ex-convict and amputee who has achieved a "constant heart" (chang-xin 常心) based on a combination of cognitive and affective attitudes characteristic of the Daoist way of life. (Fraser 2011, 100, Watson 1968, 6869, Zhuangzi 5/1-13) He has an embodied understanding of the idea that myriad things are "one" in the sense that they form a spatial-temporal whole; as a result he has no experience of loss when things transform as they do. Fraser explains that Wang Tai has no preferences and is emotionally unperturbed by even the greatest of changes, such as death, for he accepts all these changes as fixed by fate and thus beyond his control. He does not even feel intense emotions over the amputation of his foot; he sees it rather as he would the loss of a clump of dirt.

Fraser discusses one story in detail from the fourth chapter, "In the World of Men," which he believes captures the spirit of psychological health characteristic of Zhuang Zi's therapeutic project. (Fraser 2011, 98-100, Watson 1968, 59-61, Zhuangzi 4/34-53) $\mathrm{Zi} \mathrm{Gao,} \mathrm{Duke} \mathrm{of} \mathrm{She,} \mathrm{a} \mathrm{high} \mathrm{official} \mathrm{of} \mathrm{the} \mathrm{state} \mathrm{of} \mathrm{Chu,} \mathrm{is} \mathrm{having} \mathrm{a}$ conversation with Confucius. The duke has been recently assigned by the King of Chu to handle some important diplomatic affairs in the state of Qi. He doubts his ability to successfully carry out this mission and is fearful to the point of being feverish. In his conversation with Confucius, $\mathrm{Zi}$ Gao notes that Confucius had already once told him that only a person who follows the Way (dao) can handle affairs without causing one of two kinds of harms. The first concerns trouble with the balance of yin and yang, which leads to bodily health problems of the kind that the duke experienced in the story. The second kind of harm has to do with troubles in the human dao (ren dao 人道), which concerns problems in human relations and affairs. $\mathrm{Zi}$ Gao finds himself in a situation in which he cannot refuse the King's orders, and neither can he fall short of bringing about a successful outcome in his mission, for if he fails, he will surely be punished. This predicament has brought about a considerable amount of emotional strain for the duke.

While the story involves a duke on a political mission, according to Fraser, it is meant to speak not just to affairs of the state, but rather to human life more generally. The story is meant to set the stage for Confucius to discuss Daoist self-cultivation. Confucius responds to Zi Gao's predicament by saying that humans invariably find themselves in situations governed by fate. Confucius offers familial and political relationships as examples of such situations:

Confucius said, "In the world, there are two great decrees: one is fate (ming) and the other is duty ( $y i$ 義). That a son should love his parents is fate-you cannot erase this from his heart. That a subject should serve his ruler is duty-there is no place he can go and be without his ruler, no place he can escape to between heaven and earth. These are 
called the great decrees. Therefore, to serve your parents and be content to follow them anywhere - this is the perfection of filial piety. To serve your ruler and be content to do anything for him - this is the peak of loyalty. (Watson 1968, 59-60, Zhuangzi 4/39-42)

Humans are born into families and are invested in the care of their aging parents. It is part of the fate of individuals to be confronted with these circumstances. In the same way, individuals are also born into political society. It is their duty to follow the requirements that are imposed on them as political creatures. As such, they are subject to circumstances beyond their control. In order to follow the Way, the aim is to manage these and various other inevitable matters. In effectively negotiating these situations, individuals maintain the health of their minds (xin 心). The maintenance of psychological and emotional health is an important aspect of the perfection de, as Zhuang Zi's Confucius goes on to explain in the same passage:

And to serve your own mind (xin) so that sadness or joy do not sway or move it; to understand what you can do nothing about (bu-ke-nai-he 不可奈何) and to be content with it as with fate (an-zhi-ruo-ming 安之若命) — this is the perfection of virtue (de-zhi$z h i$ 德之至). As a subject and a son, you are bound to find things you cannot avoid. If you act in accordance with the state of affairs and forget about yourself, then what leisure will you have to love life and hate death? Act in this way and you will be all right. (Watson 1968, 60, Zhuangzi 4/42-44)

On Fraser's reading, the most integral part of reaching the perfection de is for individuals to accept their fate (ming). Individuals confront situations and pressures about which they cannot do anything (bu-ke-nai-he); the goal is to be at ease (an) with the inevitable (bu-de-yi). (Fraser 2011, 99) When individuals have successfully perfected their $d e$, intense emotions that disturb this inner calm can no longer threaten their equanimity. Individuals who have sufficiently perfected their de live more naturally in the sense that they are able to attend fully to their surroundings; they achieve an optimal level of efficiency and harmony in relation to their environment.

Fraser's therapeutic reading, as a psychophysical account of health, takes note of physical health as a necessary part of Zhuang Zi's vision as well as inextricably linked to the psychological and more specifically, to the emotional aspects of health. He mentions how, in early Chinese thought, emotions were understood as states of $q i$ that constitute qing (情), a term that can be translated as affections, constitution, or status. (Fraser 2011, 103-104) For Zhuang Zi, intense emotions that express joy, anger, sorrow, and delight are the result of individuals taking on the wrong cognitive and evaluative attitudes about right and wrong (shi-fei) or the wrong preferences and aversions (hao-wu) towards things. (Fraser 2011, 103-104) Zhuang Zi thinks that these attitudes are often the result of pernicious cultural influences - a mark of the artificial, i.e., of man (ren) rather than of nature (tian) - that take individuals away from their authentic selves. Zhuang Zi employs the metaphor of "bonds" and "ties" in order to describe a deficient state of being entangled in the world's affairs. The metaphor is meant to describe how certain unnatural orientations in the world, 
manifested in having certain socially induced cognitive and evaluative attitudes, bind individuals to things, which prevent them from flowing freely in their environment, as Daoist sages are able to do. The psychophysical explanation of these kinds of bonds, according to Fraser, is that the attitudes that accompany them will cause qi (energies 氣) to become fixated on some approved or disapproved, preferred or disliked, thing. This fixation creates unhealthy emotional states that are the result of culturally inculcated approvals and disapprovals or preferences and aversions. Alternatively, the $q i$ of Daoist sages flows freely through the heart and body, which corresponds to a capacity to adapt fluidly and flexibly in any situation.

Although Fraser provides a psychophysical explanation as part of his therapeutic reading, his account is incomplete without mention of various concepts that pertain specifically to physical health. Berkson has recently noted how physical health, as part of a view of nature, plays a significant role in Zhuang Zi's positive project. (Berkson 2011) ${ }^{15}$ Berkson's focus is not to lay out a therapeutic project so much as describe Zhuang Zi's normative view of how individuals should relate to their death, a substantial part of which concerns the preservation of physical health by way of individuals living out their allotted span of years (jin-nian, zhong-qi-tian-nian) and avoiding harm by being useless (wu-yong, wu-suo-ke-yong). Berkson's account, however, relates to Zhuang Zi's therapeutic project, insofar as physical integrity plays an important role in his broader notion of health.

While the perfection of de refers to psychological and emotional health, Zhuang $\mathrm{Zi}$ believes that it also facilitates the avoidance of physical harm, which he thinks is important to health more generally. When two officials from the state of Chu are sent by the King to request Zhuang Zi's service, they find Zhuang $\mathrm{Zi}$ fishing in the $\mathrm{Pu}$ River. Zhuang $\mathrm{Zi}$ has no interest in accepting the position, for to do so would mean to put himself in harm's way. Zhuang Zi responds to their request by saying,

"I have heard that there is a sacred tortoise in Chu that has been dead for three thousand years. The king keeps it wrapped in cloth and boxed, and stores it in the ancestral temple. Now would this tortoise rather be dead and have its bones left behind and honored? Or would it rather be alive and dragging its tail in the mud?"

"It would rather be alive and dragging its tail in the mud," said the two officials.

Zhuang Zi said, "Go away! I'll drag my tail in the mud!"(Watson 1968, 188, Zhuangzi $17 / 81-84)^{16}$

Humans, and perhaps all beings, possess by their nature a propensity to value life. But given their limitless desires as well as their unique capacity to think, act intentionally, and in turn stray from their nature, humans are also able to abandon their proper place in the cosmological order (Berkson 2011, 218), thereby putting their physical health at great risk. In this story, the kind of harm that Zhuang Zi has in mind is likely

\footnotetext{
${ }^{15}$ See also Coutinho and Sigurdsson (2005). In their study, they also offer a reading of Nietzsche, Zhuang $\mathrm{Zi}$, and health. Their reading of Zhuang Zi's thought employs the notions of yang-sheng (to nurture life) and zhong-qi-tian-nian (to last out one's natural years).

${ }^{16}$ I have changed all place and personal names in this passage to standard pinyin romanization.
} 
primarily psychological harm that results from the pursuit of unnatural desires, such as for wealth and power. These unnatural desires, which are, according to Zhuang $\mathrm{Zi}$, cultural inculcations that reflect unnatural attitudes as well as preferences and aversions toward things, can bring about physical harm as well as psychological harm. It is for this reason that Zhuang $\mathrm{Zi}$ advises us against their pursuit and instead endorses a way of life in which individuals lead simple and carefree lives.

In other passages, Zhuang $\mathrm{Zi}$ is more explicit about how the perfection of de facilitates invulnerability to physical harm. Daoist sages, whose de are perfected, are protected against extreme physical threats. (Berkson 2011, 205) In a passage from the first chapter, Zhuang Zi describes one such sage as totally invincible to harm: "There is nothing that can harm this man. Though flood waters pile up to the sky, he will not drown. Though a great drought melts metal and stone and scorches the earth and hills, he will not be burned." (Watson 1968, 33, Zhuangzi 1/32-33) And in the seventeenth chapter, Ruo of the North Sea tells the Lord of the River about how cultivating de in oneself increases the sage's invulnerability to physical harm. Zhuangzi writes, "When a man has perfect virtue (zhi-de), fire cannot burn him, water cannot drown him, cold and heat cannot afflict him, birds and beasts cannot injure him." (Watson 1968, 182, Zhuangzi 17/48-49) These depictions of the sage employ fantastical imagery and hyperbole to illustrate the advantages of living in accordance with the Daoist Way. The basic philosophical point is that in cultivating de, individuals are more likely able to avoid the kinds of physical harm that the pursuit of unnatural desires, such as the pursuit of power and wealth, a mark of corrupt culture, may bring about. Zhuang Zi explains at the end of the passage that the sage who has perfected his de "distinguishes between safety and danger, contents himself with fortune or misfortune, and is cautious in his comings and goings. Therefore nothing can harm him." (Watson 1968, 182, Zhuangzi 17/49-50)

Zhuang $\mathrm{Zi}$ endorses being useless (wu-yong, wu-suo-ke-yong) in order to avoid physical harm, and he employs imagery of useless trees to convey how the avoidance of harm can facilitate the goal of living out one's years. (Berkson 2011, 206) In one such story (Watson 1968, 63-65, Zhuangzi 4/64-75), a carpenter tells his apprentice to pass over a certain tree that has grown so large that people are constantly congregating around it in order to admire it. The tree is worthless, says the carpenter, because it cannot be used to make things like boats and coffins. That night, the oak tree appears to him in a dream. The tree criticizes the carpenter for his fixation on the value of being useful. It is precisely because the tree is so useless that it has been able to live so long. Other trees, such as pear trees and orange trees, die prematurely, since they are so useful. According to the tree, "Their utility makes their life miserable for them, and so they don't get to finish out the years Heaven gave them (zhong-qi-tiannian), but are cut off in mid-journey." (Watson 1968, 64, Zhuangzi 4/70-71) The tree in the dream explains that it has been trying to be of no use for a long time. (wu-suoke-yong) $)^{17}$

\footnotetext{
${ }^{17}$ See also Watson $(1968,65)$, Zhuangzi 4/75-79 for a story involving Zi Qi of Nan Bo and the useless (bu-cai 不材) tree.
} 
In the context of the human world, individuals who are useless like certain trees are able to avoid premature death, and in so doing, can live a long life. In one story involving a hunchback (Watson 1968, 66, Zhuangzi 4/83-86), Zhuang Zi offers an illustration of a Daoist exemplar that is able to preserve his physical health. Crippled Shu is severely disfigured. But it is precisely his uselessness (wu-yong) in battle that offers him the possibility of physical health in one important respect: it prevents him from having to fight in battle and meet an early death. He is able to take care of his basic needs, and although he leads a modest life, he lives in such a way as to ensure that he "finish out the years Heaven gave him" (zhong-qi-tian-nian). (Watson 1968, 66, Zhuangzi 4/86)

At first blush, the account of physical health given here seems to be in conflict with the rest of Zhuang Zi's thought. It may seem counterintuitive to think that the preservation of physical health has an important role to play in Zhuang Zi's vision. If bodily integrity plays such an important role, then why is it that so many of his Daoist exemplars are mutilated or disfigured? What if, as in the case of Shu Shan No-Toes explained below, it is an individual's fate to become disfigured in the course of his or her life? Or what if an individual is born without a limb or with serious disfigurement, as presumably was the case for Crippled Shu? If physical integrity is necessary for overall health, this would preclude the possibility of Shu Shan No-Toes and Crippled Shu attaining the normative Way (dao). If physical health is so important, one might wonder why exactly Zhuang $\mathrm{Zi}$ would praise those who, for whatever reason, fail to keep their bodies intact. ${ }^{18}$

It is clear that Zhuang $\mathrm{Zi}$ encourages individuals to keep their physical bodies intact and out of harm's way, for in doing so, individuals live in accordance with what is natural. But at the same time, Zhuang $\mathrm{Zi}$ also believes that physical health is not necessary for the achievement of his Daoist vision. I argue that even as physical health plays an important role in Zhuang Zi's therapeutic project, psychological, including emotional, health is sufficient for the achievement of Zhuang Zi's therapeutic vision. In two stories from the fifth chapter, Zhuang $\mathrm{Zi}$ suggests that psychological health is sufficient for the attainment of the normative Way. These two passages, in contrasting the wholeness of de (quan-de) with keeping the physical body (xing) whole and intact, make clear that bodily wholeness is not necessary for health, while wholeness of $d e$ is sufficient for normative health.

In the first of the two relevant stories from the fifth chapter, the mutilated Shu Shan No-Toes hobbles over to Confucius' school to request admittance, but he is denied entrance. No-Toes cannot understand why Confucius refuses to teach him simply because he was unable to preserve his body whole. No-Toes claims that he possesses "something that is worth more than a foot" (you you zun-zu-zhe cun, 猶有

\footnotetext{
${ }^{18}$ In the context of Zhuang Zi's view of death, Berkson recognizes a similar tension. On the one hand, Zhuang $\mathrm{Zi}$ accepts death; on the other hand, he endorses a view that individuals should strive to avoid it. (Berkson 2011, 192) Berkson's answer to this problem is that Zhuang Zi endorses the cultivation of life (yang-sheng 養生) generally, rather than longevity in the restricted sense of living as long as possible. (Berkson 2011, 205, 207) It seems, then, that some aspects of yang-sheng pertain to psychological health, rather than just physical health.
} 
尊足者存). (Watson 1968, 71, Zhuangzi 5/26) Confucius realizes his mistake; he decides to invite No-Toes into his school to receive the Master's teachings. But it is too late, and No-Toes has already left. Confucius tells his disciples who have witnessed this event:

Confucius said, "Be diligent, my disciples! Here is No-Toes, a man who has had his foot cut off, and still he's striving to learn so he can make up for the evil of his former conduct. How much more, then, should men whose virtue is still unimpaired (er kuang quan-de zhi $r e n h u$ 而況全德之人乎)! (Watson 1968, 71, Zhuangzi 5/28-29)

The moralist Confucius can only concern himself with outer wholeness, which is manifest in the preservation of the body, a wholeness that Confucius mistakenly conflates with an inner ability to perfect one's de. Zhuang Zi uses Confucius as a foil to illustrate the point that bodily integrity and psychological and emotional wholeness are two distinct things and that psychological health is more important than bodily integrity.

At the end of the story, No-Toes has a conversation with Lao $\mathrm{Zi}$ about why Confucius has no chance of truly understanding the Daoist vision. (Watson 1968, 72, Zhuangzi 5/29-31) In this last part of the passage, No-Toes elaborates on what it means to value "something that is worth more than a foot." It refers to an inner, rather than an outer, wholeness that pertains to a psychological and emotional reorientation. It entails a transformation of the sort in which individuals rid themselves of the pursuit of fame and reputation and have the right understanding of death, as No-Toes and his friend, the legendary Lao $\mathrm{Zi}$, explain at the end of the story.

In the story that follows the one about No-Toes, Confucius appears again in an exchange with Duke Ai of Lu. The Duke has a conversation with Confucius about a man named Ai Tai Tuo (Watson 1968, 72-74, Zhuangzi 5/31-49), a physically unattractive but highly charismatic man. He has the ability to win trust and affection without saying or doing anything in particular. Ai Tai Tuo's "capacity" (cai 才), pertains to a psychological and emotional facility that "employs the body" (shi-qixing-zhe 使其形者). (Fraser 2011，101) Confucius tells a story about some piglets who were at the body of their dead mother, in order to explain the significance of $\mathrm{Ai}$ Tai Tuo's capacity. Confucius points out that once the piglets realized that their mother was no longer alive, they left her. He explains that what the piglets loved about their mother was not her body, but what moved it. In the same way, what makes Ai Tai Tuo so special is not his body, but his capacity (cai), or wholeness of de, that employs the body. Confucius has this to say about Ai Tai Tuo and his wholeness of de (quan-de): "If so much care is taken to keep the body whole (xing-quan 形全), how much more in the case of a man whose virtue is whole (er kuang quan-de zhi-ren $h u$ )?" (Watson 1968, 73, Zhuangzi 5/41-42) In the passages about No-Toes and Ai Tai Tuo, we have seen how the cultivation of de, which concerns psychological health, is contrasted with bodily health. While it is true that Zhuangist health relates to physical as well as psychological health, the latter is given distinct priority over the 
former, to such a degree that psychological health is even understood as being sufficient for the attainment of the normative Way.

In the present study, I have argued that both Nietzsche and Zhuang $\mathrm{Zi}$ endorse a notion of health. The concept of health relies on a theory of nature, which informs a normative project. It asserts the view that descriptive metaphysics provides a basis for normative ethics. It is a value laden account, in that particular descriptive features of human nature are picked out as relevant to a normative account of how human beings ought to live. Nietzsche and Zhuang $\mathrm{Zi}$ conceive their respective visions in therapeutic terms, in the sense that each vision depends on the health of human beings. While each normative view contains its own respective conception of the healthy human being, the goal for both philosophers is to align individuals with their authentic natures. Both conceptions of health also assert that culture is an obstacle to the achievement of living naturally. For Nietzsche, ascetic morality as a cultural development stands in the way of living in accordance with will to power; for Zhuang $\mathrm{Zi}$, having unnatural attitudes and preferences and aversions, also a product of culture, are the greatest obstacle to living in accordance with the normative Way.

But while the normative projects of Nietzsche and Zhuang $\mathrm{Zi}$ share in certain structural features, the specific content that make up each of their respective visions is radically dissimilar. For a start, both Nietzsche and Zhuang Zi differ in terms of what they take to be pernicious cultural influences, as the previous paragraph makes clear. In addition, Nietzschean health requires that individuals replace existing morality with new standards of value continuous with will to power, while Zhuangist health requires that individuals cultivate the perfection (zhi) or wholeness (quan) of de, which involves disabusing individuals of any and all values.

In an article that lays out a novel reading of Aristotle's ethics, McDowell discusses in what sense he believes the great philosopher employs a metaphysical theory of nature to inform a normative view. Given that humans lack a preexisting normative order, descriptive metaphysics will never be able to fully bridge the gap between itself and normative ethics. McDowell's Aristotle believes that humans must posit values that are in some important sense continuous with human nature-they are naturally made, not naturally given. In the context of the thought of Aristotle, McDowell distinguishes between two distinct senses of nature that require teasing apart. There is a "mere" or first nature that serves as a basic given concerning who we are as human beings. Practical reasoning can be employed, and with its aid, humans can ultimately embody a "second" nature. Aristotle's virtues are in fact independent of mere nature and need to be developed as part of a second nature. (McDowell 1998)

Whether McDowell's interpretation of Aristotle's ethics is on point is beyond the scope of the present study. McDowell's distinction helps make apparent an important difference in Nietzsche's and Zhuang Zi's therapeutic projects. First, Nietzsche would find the distinction between mere and second nature helpful for articulating his view of health. Nietzsche argues that there are certain natural facts about human beings that should be taken into consideration in a normative account. But humans are also unusual in the animal kingdom, as the "as yet undetermined animal." (Nietzsche 2000a, 264) Brute nature by itself cannot tell individuals how to live; they must posit 
values in order to lead healthy lives. Like McDowell's Aristotle, Nietzsche believes that humans must posit values that are in some important sense continuous with human nature - they are naturally made, not naturally given. While these values can be established to some degree on the basis of the basic human desires mentioned above, it seems that by themselves they are insufficient for creating values that facilitate health. Even as will to power provides a constraint defining how humans ought to live, it cannot offer on its own a comprehensive set of normative standards that guide human life. Zhuang Zi's notion of nature serves as an important point of contrast; McDowell's Aristotle would, of course, be incompatible with Zhuang Zi's version of health. In the context of normative ethics, Zhuang $\mathrm{Zi}$ believes that the attainment of the normative Way requires that humans ground an experiential or embodied knowledge, as opposed to a theoretical knowledge, of how to live squarely in notions of what the world is like. In relying on an embodied knowledge of the way things are, Zhuang Zi's view requires only that aspect of human nature that is given, what McDowell calls mere nature.

While there is a clear disagreement both in their respective views of nature-as well as in their respective concepts of normative health that flow from these views of nature-Nietzsche and Zhuang Zi differ from McDowell and Aristotle in highlighting the importance of disabusing individuals of pernicious cultural influences, so as to achieve health. There is, of course, no reason to think that McDowell's characterization of the good life has to conform to conventional morality. But that McDowell locates ethical upbringing as the locus from which ethical life begins and is cultivated might suggest its continuance in one form or another, rather than its dissolution. Nietzsche and Zhuang Zi believe that it is possible to conceive of wholly different ways of living, even if individuals cannot initially fully understand what their respective visions entail. Individuals can only actualize these possibilities if they question the very conventional thinking that underpins their moral upbringing. Despite the fact that the details of Nietzsche's and Zhuang Zi's respective visions are starkly different, we must not overlook the structural similarities that exist in connection to their therapeutic visions. Both thinkers of this study, as part of a robust notion of health, highlight the importance of living naturally and insist on disabusing individuals of conventional ways of thinking, perceiving, and behaving, in order to accomplish a state of health.

\section{ACKNOWLEDGEMENTS}

I owe many thanks to Charles Goodman, Robert Guay, Nick Kaldis, and two anonymous referees of Comparative Philosophy for providing helpful critical feedback on previous drafts. 


\section{REFERENCES}

Aristotle (1999), Nicomachean Ethics, trans. Terence Irwin (Indianapolis: Hackett).

Berkson, Mark (2011), "Death in the Zhuangzi: Mind, Nature, and the Art of Forgetting," in Amy Olberding and Philip J. Ivanhoe (eds.), Mortality in Traditional Chinese Thought (Albany: State University of New York), 191-224.

Clark, Maudemarie and Dudrick, David (2012), The Soul of Nietzsche's Beyond Good and Evil (New York: Cambridge University).

Frankfurt, Harry G. (1971), "Freedom of the Will and the Concept of a Person," The Journal of Philosophy, 68: 5-20.

Fraser, Chris (2011), "Emotion and Agency in Zhuangzi," Asian Philosophy, 21 (1): 97-121.

Fung Yu-Lan (1976), "The Third Phase of Taoism: Chuang Tzu," in Derek Bodde (ed.), A Short History of Chinese Philosophy: A Systematic Account of Chinese Thought From Its Origins to the Present Day (New York: The Free Press), 104117.

Geuss, Raymond (1997), "Nietzsche and Morality," European Journal of Philosophy, 5 (1): $1-20$.

Hall, David (1984), "Nietzsche and Chuang Tzu: Resources for the Transcendence of Culture," Journal of Chinese Philosophy, 11 (2): 139-152.

Ivanhoe, Philip J. (trans./ed.) (2002), The Daodejing of Laozi (Indianapolis: Hackett).

Janaway, Christopher (2007), Beyond Selflessness: Reading Nietzsche's Genealogy (New York: Oxford University).

Katsafanas, Paul (2013), "Nietzsche's Philosophical Psychology," in John Richardson and Ken Gemes (eds.), Oxford Handbook of Nietzsche (Oxford: Oxford University), 727-755.

Lawton Jr., Philip (1987/1988), "Nietzsche's Convalescence," Philosophy Research Archives, 13: 151-179.

Leiter, Brian (2002), Nietzsche on Morality (New York: Routledge).

Letteri, Mark (1990), "The Theme of Health in Nietzsche's Thought," Man and World, 23 (4): 405-417.

Long, Thomas (1990), "Nietzsche's Philosophy of Medicine," Nietzsche-Studien, 19: 112-128.

McDowell, John (1998), “Two Sorts of Naturalism," in McDowell, Mind, Value, and Reality (Cambridge, MA: Harvard University), 167-197.

Nehamas, Alexander (1985), Nietzsche: Life as Literature (Cambridge, MA: Harvard University).

Nietzsche, Friedrich (1968), Thus Spoke Zarathustra, trans. Walter Kaufmann in Kaufmann (ed.), The Portable Nietzsche (New York: The Viking Press), 115-439.

- (1974), The Gay Science, trans. Walter Kaufmann (New York: Vintage).

- (1997), Daybreak: Thoughts on the Prejudices of Morality, trans. R. J. Hollingdale (New York: Cambridge University). 
- Nietzsche, Friedrich (2000a), Beyond Good and Evil, trans. Walter Kaufmann in Kaufmann (ed.), Basic Writings of Nietzsche (New York: The Modern Library), 179-436.

- Nietzsche, Friedrich (2000b), On the Genealogy of Morals, trans. Walter Kaufmann in Kaufmann (ed.), Basic Writings of Nietzsche (New York: The Modern Library), 437-599.

Nussbaum, Martha (1994), The Therapy of Desire: Theory and Practice in Hellenistic Ethics (Princeton: Princeton University).

Parkes, Graham (1994), Composing the Soul: Reaches of Nietzsche's Psychology (Chicago: University of Chicago).

Reginster, Bernard (2006), The Affirmation of Life: Nietzsche on Overcoming Nihilism (Cambridge, MA: Harvard University).

Richardson, John (1996), Nietzsche's System (New York: Oxford University).

Schacht, Richard (1983), Nietzsche (London: Routledge).

Swanton, Christine (2005), "Nietzschean Virtue Ethics," in Christa Davis Acampora (ed.), Nietzsche's On the Genealogy of Morals: Critical Essays (Lanham, MD: Rowman and Littlefield), 291-303.

Welshon, Robert (1992), "Nietzsche's Peculiar Virtues and the Health of the Soul," International Studies in Philosophy, 24.2: 77-89.

Watson, Burton (trans.) (1968), The Complete Works of Chuang Tzu (New York: Columbia University).

Zhuang Zi (1956), A Concordance to Zhuangzi (《莊子引得》Zhuangzi Yingde). Harvard-Yenching Institute Sinological Index Series, Supplement no. 20 (Cambridge, MA: Harvard University). 